\title{
Black esophagus
}

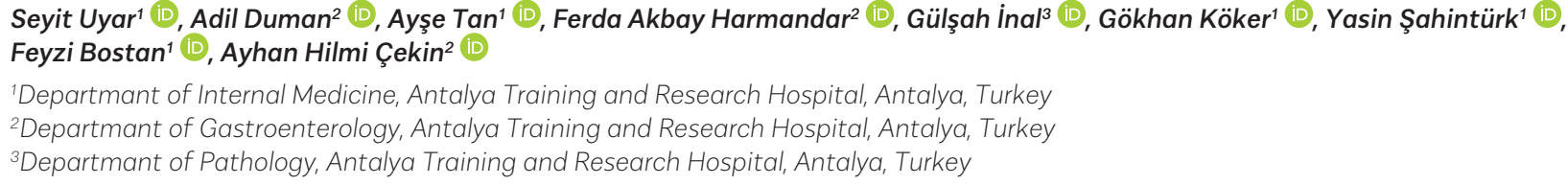

Cite this article as: Uyar S, Duman A, Tan A, et al. Black esophagus. Turk J Gastroenterol 2019; 30(11): 986-7.

\section{QUESTION}

A 64-year-old male with history of diabetes mellitus and hypertension was hospitalized for diabetic ketoacidosis at our internal medicine clinic, and intravenous fluid and insulin were started. The patient appeared dehydrated; his blood pressure was $110 / 70 \mathrm{mmHg}$ and heart rate was $84 \mathrm{bpm}$. Initial laboratory analyses revealed a blood glucose level of $431 \mathrm{mg} / \mathrm{dL}$, a serum creatinine level of 1.3 $\mathrm{mg} / \mathrm{dL}$, an arterial blood $\mathrm{pH}$ of 7.18 , a urinary ketone level of $3+$, and a normal complete blood count. After 3 days, the patient was given oral diet on recovery of diabetic ketoacidosis. However, he complained worsening of nausea and vomiting, and esophagogastroduodenosco- py showed a diffuse circumferential black appearance throughout the entire esophagus mucosa (Figure 1). Thoracic and abdominal computed tomographic angiography showed advanced stenosis of bilateral proximal renal arteries with no pathology in esophageal vasculature. The patient was diagnosed with polyarteritis nodosa on nephrology consultation, and $40 \mathrm{mg} /$ day methylprednisolone was started. Second endoscopy performed 6 days later showed the black appearance again, slightly reduced than before, and white exudative secretions (Figure 2). Biopsy was taken in this endoscopy; it could not be taken in the first endoscopy because of perforation risk.

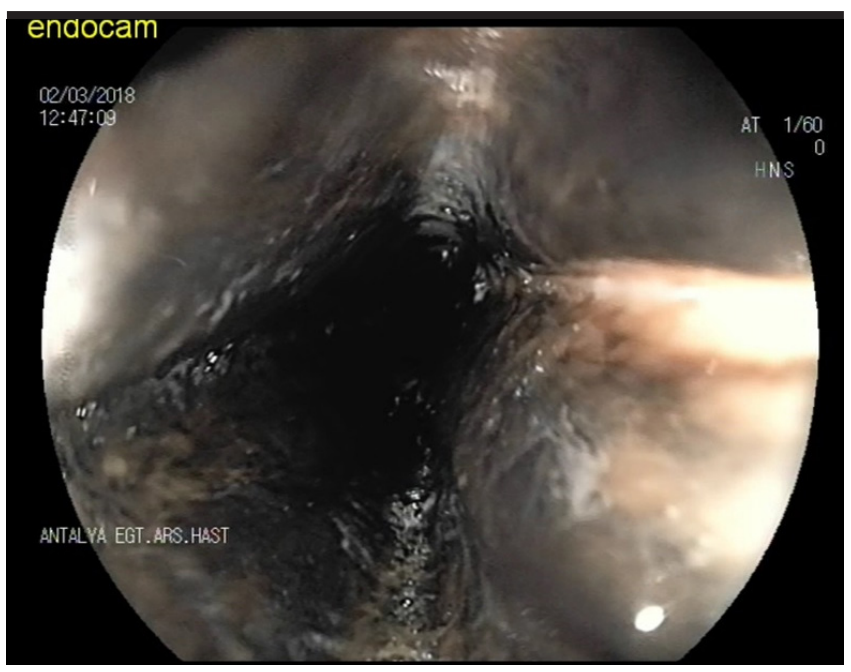

Figure 1. First endoscopic view of black esophagus

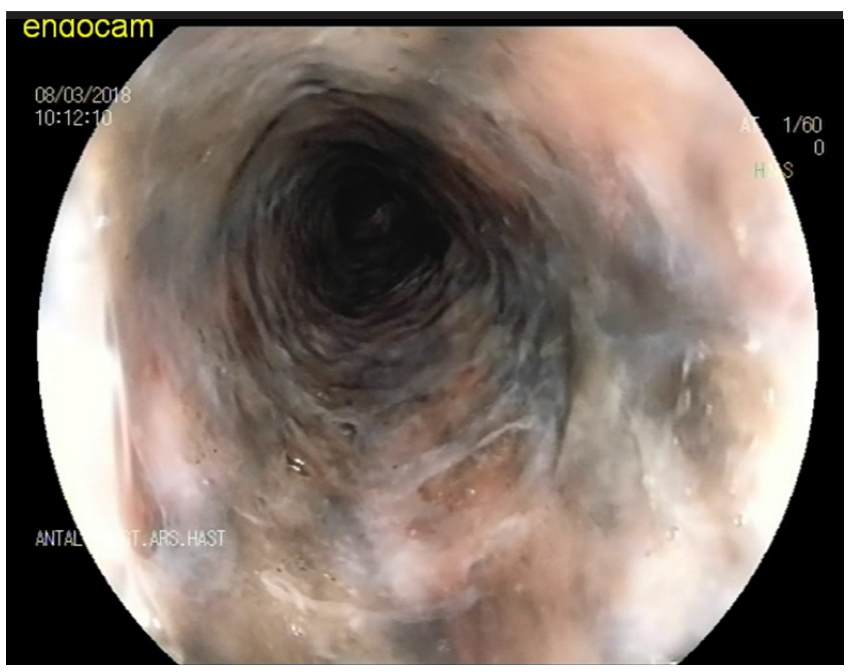

Figure 2. One week later endoskopic view of black esophagus with white exudative secretions

Corresponding Author: Seyit Uyar; seyituyar79@hotmail.com Received: January 3, 2019 Accepted: February, 2019

(C) Copyright 2019 by The Turkish Society of Gastroenterology · Available online at www.turkjgastroenterol.org DOI: 10.5152/tjg.2019.181019 


\section{ANSWER}

\section{Black esophagus}

The patient was diagnosed with acute esophageal necrosis (AEN), and oral intake was terminated; intravenous proton pump inhibitor and fluid replacement were started. Histological evaluation revealed necrotic appearance, and AEN was confirmed; numerous thin fungal hyphae structures similar to Candida hyphae and spores among intensive and mixed inflammatory infiltration were also seen (Figure 3). Accordingly, fluconazole treatment was administered for 14 days.

The black appearance of esophagus is a rare and recently described syndrome and generally caused by AEN (1). Besides AEN, malignant melanoma, acanthosis nigricans, coal dust deposition, pseudomelanosis, and melanocytosis of the esophagus may cause the black appearence in the esophagus (1). Case reports of AEN have been increasing in recent years, and it should be included in the differential diagnosis of upper gastrointestinal bleeding. The etiology of black esophagus is not clearly known. Vascular hypoperfusion due to patient's medical condition resulting in tissue damage is the most commonly implicated etiological mechanism. Diabetes mellitus, atherosclerosis, cardiovascular and renal diseases, sepsis, blood loss, trauma, hypothermia, and shock are important risk factors that may lead to hemodynamic instability and AEN (1).

Local bacterial, viral, and fungal infections may also be associated with AEN; therefore, biopsy specimens should be sent for cultures to exclude infectious etiologies or superimposed infection (1). Candida species are considered

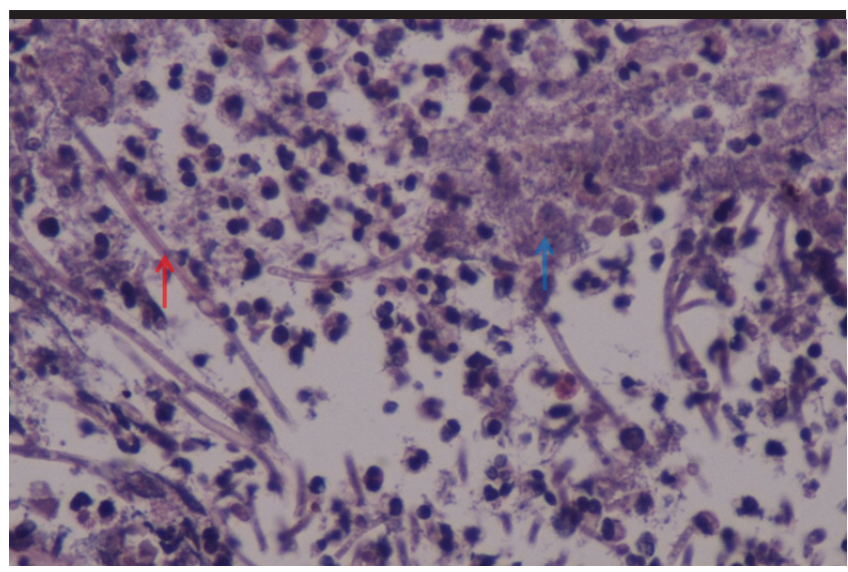

Figure 3. Histological appearance of Candida hyphaes (red arrow) and necrosis (blue arrow) in 40x esophagus tissue to be part of the normal microbiota in the oropharyngeal cavity and gastrointestinal and genitourinary tracts of humans, but they can cause opportunistic infection under immunosuppressed conditions (2). The coexistence of Candida and AEN is a rare condition, and few case reports are available in the literature $(3,4)$.

There is no specific treatment of AEN; restoring hemodynamic stability by correcting underlying diseases, administering intravenous proton pump inhibitors, and oral intake restriction is the general treatment approach (5). Esophageal perforation is the major complication of AEN and seen in $<7 \%$ of the cases (5). While mortality rates were high in the initial cases, it decreased to $6 \%$ in the following publications (5). Esophageal stenosis and stricture formation can be seen in $>10 \%$ of patients and requires endoscopic dilation and long term follow-up (1).

Peer-review: Externally peer-reviewed.

Author Contributions: Concept - F.A.H.; Design - G.I.; Supervision - S.U.; Resources - A.T.; Materials - G.K.; Data Collection and/or Processing - Y.S..; Analysis and/or Interpretation - S.U., A.D.; Literature Search - F.B.; Writing Manuscript - S.U.; Critical Review - A.H.Ç.

Conflict of Interest: The authors have no conflict of interest to declare.

Financial Disclosure: The authors declared that this study has received no financial support.

\section{REFERENCES}

1. Gurvits GE. Black esophagus: acute esophageal necrosis syndrome. World J Gastroenterol 2010; 16: 3219-25. [CrossRef] 2. Naglik JR, Challacombe SJ, Hube B. Candida albicans secreted aspartyl proteinases in virulence and pathogenesis. Microbiol Mol Biol Rev 2003; 67: 400. [CrossRef]

3. Kim YH, Choi SY. Black esophagus with concomitant candidiasis developed after diabetic ketoacidosis. World J Gastroenterol 2007; 13: 5662-3. [CrossRef]

4. Pereira O, Figueira-Coelho J, Picado B, Costa JN. Black oesophagus. BMJ Case Rep 2013; 2013. pii: bcr2012008188. [CrossRef]

5. Gurvits GE, Cherian K, Shami MN, et al. Black esophagus: new insights and multicenter international experience in 2014. Dig Dis Sci 2015; 60: 444-53. [CrossRef] 